\title{
IDENTIFIKASI TEKSTUR UNTUK KLASIFIKASI BATUAN BEKU DENGAN METODE DISCRETE WAVELET TRANSFORM (DWT) DAN SUPPORT VECTOR MACHINE (SVM)
}

\author{
Abu Amar Tantowi ${ }^{1}$, Bambang Hidayat ${ }^{2}$, Andri Slamet Subandrio ${ }^{3}$, \\ 1, 2 Fakultas Teknik Elektro, Universitas Telkom \\ ${ }^{3}$ Fakultas Ilmu dan Teknologi Kebumian, Institut Teknologi Bandung \\ 1abuamart@student.telkomuniversity.ac.id, 2bhidayat@telkomuniversity.ac.id, \\ 3andrissm@gmail.com
}

\begin{abstract}
Abstrak
Petrologi adalah bidang ilmu geologi yang terfokus pada studi mengenai batuan dan kondisi pembentukannya. Petrografi adalah cabang dari petrologi yang menjelaskan deskripsi rinci dari batuan berdasarkan kandungan mineral dan tekstur. Batuan merupakan sekumpulan mineral yang membeku, mineral tersebut umumnya disebut sebagai rock-forming minerals. Dengan mengidentifikasi masing-masing mineral yang terdapat pada batuan dengan bantuan mikroskop, pengklasifikasian dapat dilakukan. Karakteristik dari tiap-tiap jenis batuan tersebut dapat dibedakan dari persentase mineral-mineral yang membentuk batuan tersebut. Mikroskop petrografi dapat menganalisis secara rinci dari mineral dengan mineralogi optik dan sayatan tipis dari batuan. Saat ini, petrografer menggunakan cara konvensional untuk menelitinya dengan menggunakan indera penglihatan. Dalam artikel ini, dilakukan perancangan sebuah perangkat lunak berbasis MATLAB yang dapat mengklasifikasikan jenis-jenis dari batuan. Input dari sistem ini berupa citra digital dari batuan, yang secara mikroskopis diambil dari mikroskop petrografi. Kemudian citra tersebut diolah oleh sistem. Proses pertama adalah pengekstraksian ciri melalui metode Discrete Wavelet Transform (DWT). Selanjutnya dilakukan proses klasifikasi citra melalui metode Support Vector Machine (SVM). Dari hasil pengujian yang dilakukan, didapat akurasi terbaik 83.9506\%.
\end{abstract}

Kata Kunci: Petrologi, Petrografi, DWT, SVM

\section{Abstract}

Petrology is a field of geological science focused on the study of rock and its forming conditions. Petrography is a branch of petrology that explains detailed descriptions of rocks, based on mineral content and texture. Rocks are a collection of minerals that freeze. These minerals are generally referred to as rock-forming minerals. By identifying each of the minerals in the rock, using a microscope, classifications can be done. Characteristics of each type of rock can be distinguished from the percentage of minerals from the rock. Currently, petrographers use conventional method to examine the rock, using manual vision. This method is low in term of a accuracy and time efficiency. In this work, the authors designed a MATLAB-based software that can classify the types of rocks. The system input in the form of digital images of the rocks microscopically taken from a petrographic microscope, and furthermore was processed by the system. The first process is an extraction feature through Discrete Wavelet Transform (DWT). Next is the image classification process through the Support Vector Machine (SVM) method. From the results, highest accuracy obtained is $83.9506 \%$.

Key Words: Petrology, Petrography, DWT, SVM

\section{Pendahuluan}

Petrografi adalah cabang ilmu petrologi yang berfokus pada deskripsi dan klasifikasi batuan [1]. Klasifikasi batuan tersebut didasarkan pada persentase volume dari berbagai macam mineral pembentuk batuan (rock-forming minerals). Berdasarkan proses pembentukannya, batuan dibagi menjadi 3 , yaitu batuan beku yang terbentuk dari proses pembekuan atau kristalisasi lava, batuan sedimen yang terbentuk dari proses pengendapan, dan batuan metamorf yang terbentuk dari proses metamorfisme.

Para ahli geologi saat ini mengklasifikasikan batuan tersebut dengan menggunakan indera penglihatan dan bantuan mikroskop petrografi. Cara ini masih memiliki 
kelemahan dan tingkat akurasi yang rendah dari hasil pengamatan masih diestimasi. Dari permasalahan tersebut, diadakan penelitian untuk merancang suatu program yang dapat mengidentifikasi dan mengklasifikasi batuan dengan citra digital. Diharapkan, hasil penelitia ini dapat membantu para ahli geologi dalam mengindentifikasi dan mengklasifikasi batuan dengan tingkat akurasi yang tinggi dan durasi yang cepat.

Penelitian yang berjudul Identifikasi dan Klasifikasi Jenis Batuan Beku dengan Metode Ekstraksi Ciri Discrete Wavelet Transform dan Klasifikasi Support Vector Machine ini merupakan pengembangan dari penelitian sebelumnya [2]. Perbedaannya yaitu pada citra yang diambil pada penelitian ini adalah citra mikroskopis dan metode yang berbeda. Program yang dirancang menggunakan perangkat lunak MATLAB versi R2017a.

Pada penelitian ini, dilakukan perancangan sistem untuk mengidentifikasi dan klasifikasi bahan dengan metode DWT dan SVM. Performansi sistem dilakukan berdasarkan akurasi dan durasi sistem.

\section{Dasar Teori}

\subsection{Batuan Beku}

Batuan beku adalah batuan yang berasal dari cairan magma yang membeku akibat mengalami pendinginan. Menurut ilmu petrologi semua material beku terbentuk dari magma yang mengandung lelehan silikat yang cair dan pijar kemudian membeku [3]. Magma dengan ciri-ciri cair dan pijar tersebut berada di dalam bumi. Karena kekuatan gas yang larut di dalamnya, magma tersebut naik ke atas bumi mencari tempat-tempat yang rapuh dalam kerak bumi seperti daerah patahan/rekahan. Magma akan keluar ke permukaan bumi melalui pipa gunung api. Magma yang keluar tersebut disebut dengan lava, akan tetapi ada magma yang membeku di dalam bumi dan disebut batuan beku dalam [1].

\subsubsection{Komposisi Batuan Beku}

Komposisi batuan beku (99\%) terdiri dari unsur-unsur utama seperti Oksigen, Silikon, Alumunium, Kalsium, Sodium, Potassium dan Magnesium. Unsur-unsur tersebut membentuk mineral silikat yaitu Felspar, Olivin, Piroksen, Amfibol, Kuarsa dan Mika. Komposisi mineral dari batuan berhubungan dengan sifat warna batuan. Batuan yang banyak mengandung mineral silika dan alumina akan cenderung berwarna terang, sedangkan yang banyak mengandung magnesium, besi dan kalsium umumnya mempunyai warna yang gelap.

\subsubsection{Tekstur Batuan Beku}

Tekstur pada batuan beku dapat menggambarkan proses dari pembekuan magma pada tempat pembekuannya dan pencerminan dari mineralogi dari batuan tersebut. Tekstur adalah kenampakkan dari bentuk, ukuran dan hubungan keteraturan butiran atau kristal dalam batuan [1].

\subsection{Citra Digital}

Secara harfiah, citra adalah gambar pada bidang dua dimensi (dwimatra). Dilihat dari sudut pandang matematis, citra adalah fungsi menerus (сопtinue) dari intensitas cahaya pada bidang dua dimensi. Sumber cahaya yang menerangi objek, dan objek memantulkan sebagian dari berkas cahaya tersebut. Pantulan cahaya tersebut ditangkap oleh alat-alat optik, seperti mata pada manusia, kamera, pemindai (scanner), dan sebagainya, sehingga bayangan objek atau citra tersebut terekam [4]. Agar dapat diolah dengan computer digital, sebuah citra harus direpresentasikan secara numerik menggunakan nilai-nilai diskrit. Representasi citra dari fungsi malar (kontinu) menjadi nilai-nilai diskrit disebut dengan digitalisasi. Citra yang dihasilkan tersebut disebut sebagai citra digital (digital image). Secara umum, citra digital berbentuk empat persegi panjang, dan dimensi ukurannya dinyatakan dalam tinggi $\mathrm{x}$ lebar (atau lebar $\mathrm{x}$ panjang) [5].

Citra digital dengan tinggi $N$, lebar $M$, dan $L$ derajat keabuan dapat dianggap sebagai fungsi seperti pada persamaan (1)

$$
f(x, y)=\left\{\begin{array}{l}
0 \leq x \leq M \\
0 \leq y \leq N \\
0 \leq f \leq L
\end{array}\right.
$$

\subsection{Discrete Wavelet Transform}

Discrete Wavelet Transform (DWT) merupakan proses dekomposisi citra pada level dekomposisi tertentu, dimana pada setiap level dekomposisi dilakukan proses melewatkan sinyal frekuensi tinggi (high pass filter) dan frekuensi rendah (low pass filter). Setelah itu dilakukan proses sub band, dimana mengambil sampel dari setengah keluaran pada masing-masing filter tersebut diambil.

Wavelet berasal dari sebuah fungsi penyekala (scaling function). Fungsi ini dapat membuat sebuah induk wavelet (mother wavelet). Wavelet didasarkan pada pembangkitan sejumlah tapis (filter) dengan cara menggeser dan menskala mother wavelet. Penambahan dan pengurangan skala akan mempengaruhi durasi waktu, lebar bidang (bandwidth) dan nilai frekuensi [6]. Untuk alur proses dekomposisi pada DWT, dapat dilihat pada Gambar 1.

\subsection{Support Vector Machine}

Support Vector Machine (SVM) adalah suatu teknik yang relatif baru untuk melakukan prediksi, baik dalam kasus klasifikasi maupun regreai, yang sangat popular beakangan ini [7]. SVM dikembangkan oleh 


\section{Two-Dimensional DWT}

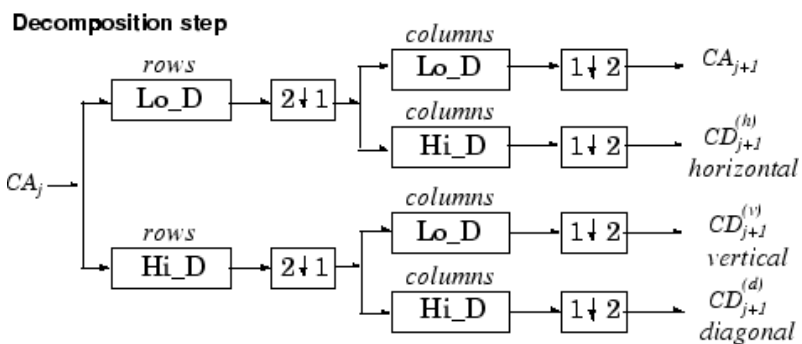

Gambar 1. Diagram Alur Proses DWT
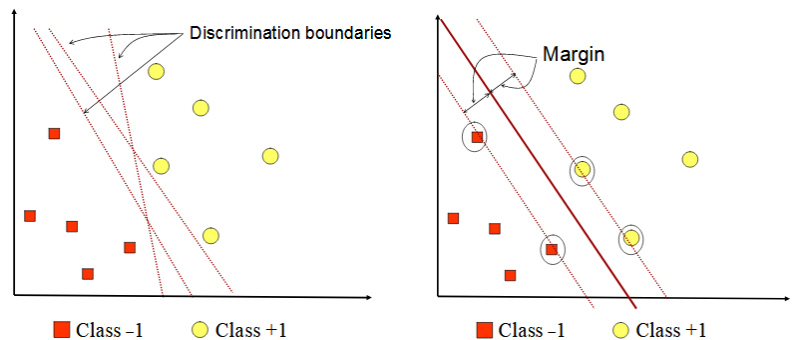

Gambar 2. SVM menentukan hyperlane antara dua kelas

Boser, Guyon, Vapnik, dan pertama kali dipresentasikan pada tahun 1992 di Annual Workshop on Computational Learning Theory [8]. Konsep dasar SVM sebenarnya merupakan kombinasi harmonis dari teori-teori komputasi yang telah ada puluhan tahun sebelumnya, seperti margin hyperlane (Duda \& Hart tahun 1973, Cover tahun 1965, Vapnik 1964, dsb), kernel diperkenalkan oleh Aronszajn tahun 1950, dan demikian juga dengan konsep-konsep pendukung yang lain [7].

Konsep SVM dapat dijelaskan secara sederhana sebagai usaha mencari hyperlane terbaik yang berfungsi sebagai pemisah dua buah class pada input space. Gambar 2 memperlihatkan beberapa pattern yang merupakan anggota dari dua buah class : +1 dan -1 . Pattern yang tergabung pada class -1 disimbolkan dengan warna merah (kotak), sedangkan pattern pada class +1 , disimbolkan dengan warna kuning (lingkaran). Problem klasifikasi dapat diterjemahkan dengan usaha menemukan garis (hyperlane) yang memisahkan antara kedua kelompok tersebut [6].

Untuk menemukan hyperlane, terdapat cara yang disebut trik kernel. Kernel-kernel pada Tabel 1 merupakan fungsi untuk mempermudah menemukan hyperlane.

\section{Perancangan Sistem}

Sistem yang dirancang pada penelitian ini bertujuan agar dapat membantu analisa ahli geologi dalam mengidentifikasi suatu batuan beku berdasarkan tekstur
Tabel 1. Kernel SVM.

\begin{tabular}{|l|c|}
\hline Jenis Kernel & Definisi \\
\hline Polynomial & $K\left(\vec{x}_{i}, \vec{x}_{j}\right)=\left(\vec{x}_{i} \cdot \vec{x}_{j}+1\right)^{p}$ \\
\hline Gausssian & $K(2)$ \\
& $K\left(\vec{x}_{i}, \vec{x}_{j}\right)=\exp \left(-\frac{\left|\vec{x}_{i}-\vec{x}_{j}\right|^{2}}{2 \sigma^{2}}\right)$ \\
\hline Linear & $K\left(\vec{x}_{i}, \vec{x}_{j}\right)=\vec{x}_{i} \cdot \vec{x}_{j}$ \\
\hline Signoid & $K\left(\vec{x}_{i}, \vec{x}_{j}\right)=\tanh \left(\alpha \vec{x}_{i} \cdot \vec{x}_{j}+\beta\right)$ \\
\end{tabular}

dan warna dari batuan beku tersebut. Gambar 2 menunjukan diagram alur sistem secara keseluruhan yang dimulai dari input citra, preprocessing, ekstraksi ciri, dan klasifikasi.

Pada bagian preprocessing, citra yang masuk ke sistem dilakukan beberapa penyesuaian terlebih dahulu. Tahapan preprocessing terdiri dari Resize dan RGB to Grayscale, yang berfungsi agar semua citra memiliki ukuran resolusi yang sama satu sama lain dan mengubah format warna citra dari RGB ke Grayscale.

Pada Gambar 4 merupakan citra input yang masuk ke dalam sistem dan akan masuk ke tahap preprocessing. Gambar 5 merupakan citra hasil preprocessing yang telah di-resize dan grayscale.

\section{Analisis}

\subsection{Pengujian sub band DWT}

Pada pengujian skenario 1, ukuran citra yang digunakan adalah 1024 x 684 piksel, kernel SVM yang digunakan yaitu Gaussian, level dekomposisi 1, jumlah citra cross nikol yaitu 246 citra latih dan 155 citra uji sedangkan untuk jumlah citra paralel nikol yaitu 250 citra latih dan 162 citra uji. Citra tersebut dibagi ke dalam 6 kelas.

Dari Tabel 2 dapat dilihat bahwa untuk citra cross nikol akurasi tertinggi didapat $78.064 \%$, dengan waktu 103.2356 detik, sedangkan untuk citra paralel nikol akurasi tertinggi didapat $83.950 \%$ dengan waktu 114.2539 detik. Dari pengujian didapat subband LL memiliki tingkat akurasi tertinggi dikarenakan subband LL paling banyak menyimpan informasi dari citra.

Gambar 6 menjelaskan tentang akurasi pada skenario 1, dimana nilai akurasi paralel selalu lebih tinggi di subband manapun. Hal tersebut bisa terjadi 


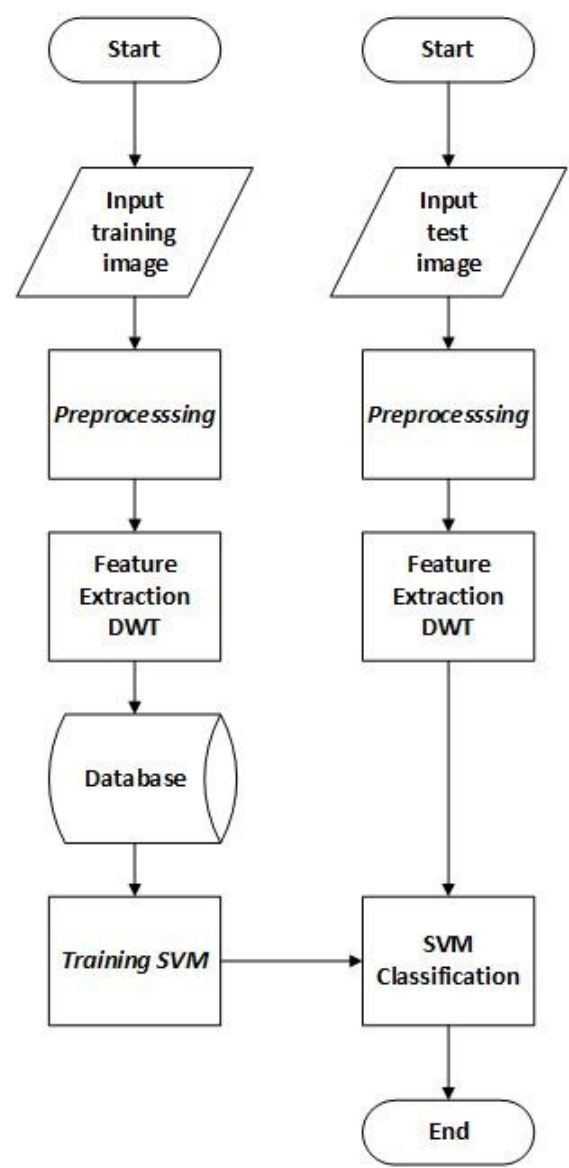

Gambar 3. Diagram Alur Sistem

Tabel 2. Hasil Pengujian Skenario 1

\begin{tabular}{|l|c|l|r|r|}
\hline \multirow{2}{*}{ Subband } & \multicolumn{2}{|c|}{ Cross Nikol } & \multicolumn{2}{c|}{ Paralel Nikol } \\
\cline { 2 - 5 } & $\begin{array}{l}\text { Akurasi } \\
(\%)\end{array}$ & $\begin{array}{l}\text { Waktu } \\
\text { (detik) }\end{array}$ & $\begin{array}{l}\text { Akurasi } \\
(\%)\end{array}$ & $\begin{array}{l}\text { Waktu } \\
\text { (detik) }\end{array}$ \\
\hline LL & 78.064 & 106.244 & 83.950 & 114.253 \\
\hline LH & 77.419 & 120.766 & 77.777 & 106.316 \\
\hline HL & 76.774 & 103.235 & 80.86 & 112.504 \\
\hline HH & 67.741 & 96.119 & 70.370 & 168.408 \\
\hline $\begin{array}{l}\text { Semua } \\
\text { subband }\end{array}$ & 70.322 & 106.061 & 73.456 & 188.375 \\
\hline
\end{tabular}

karena efektifitas paralel lebih baik daripada cross. Berbeda dengan hasil penelitian pada durasi skenario seperti Gambar 7, dimana nilai parallel pada durasi wakti lebih tinggi. Nilai tertinggi didapatkan dri subband HL, $\mathrm{HH}$. Akan tetapi durasi terendah diperoleh di HH dengan waktu cross.

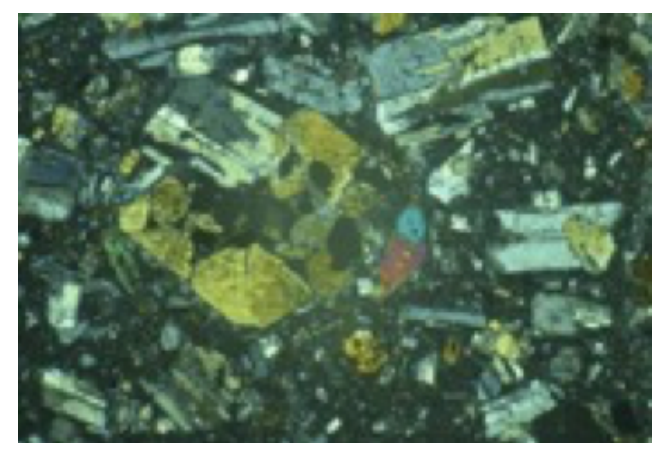

Gambar 4. Hasil Akuisisi Citra.

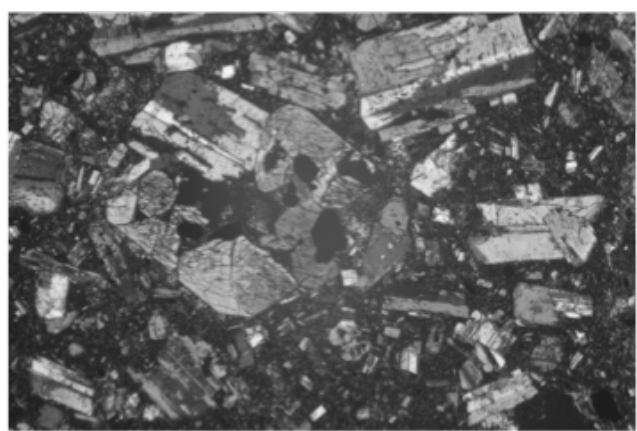

Gambar 5. Hasil Preprocessing Citra.

Akurasi

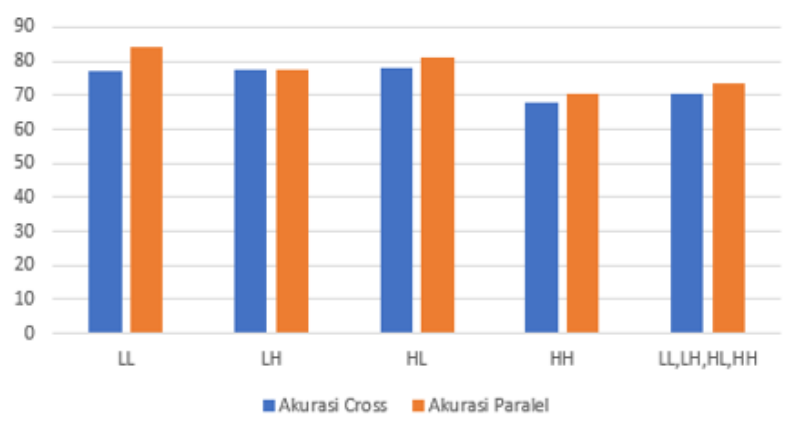

Gambar 6. Grafik akurasi skenario 1.

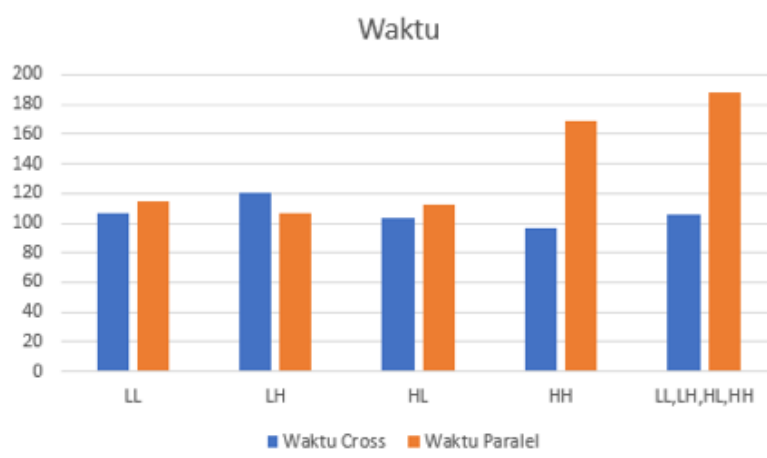

Gambar 7. Grafik waktu skenario 1. 


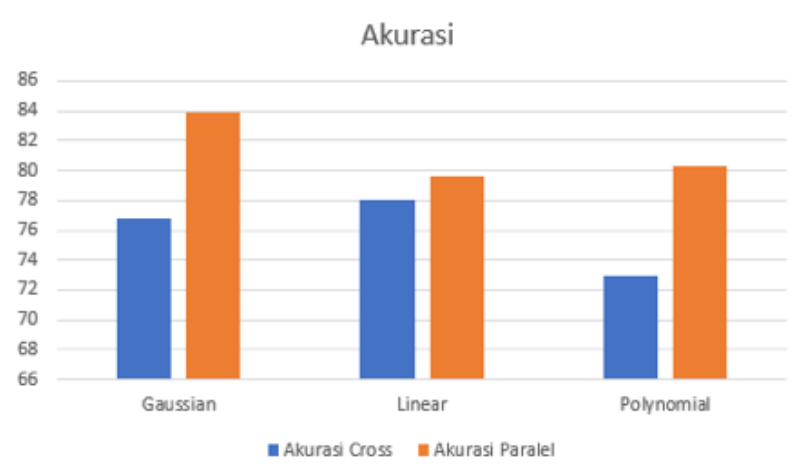

Gambar 8. Grafik akurasi skenario 2.

\subsection{Pengujian kernel SVM}

Pada pengujian skenario 2, ukuran citra yang digunakan adalah 1024 x 684 piksel, subband DWT yang digunakan adalah LL, level dekomposisi 1, jumlah citra cross nikol yaitu 246 citra latih dan 155 citra uji sedangkan untuk jumlah citra paralel nikol yaitu 250 citra latih dan 162 citra uji. Citra tersebut dibagi ke dalam 6 kelas.

Tabel 3. Hasil Pengujian Skenario 2

\begin{tabular}{|l|c|c|c|c|}
\hline \multirow{2}{*}{$\begin{array}{c}\text { Kernel } \\
\text { SVM }\end{array}$} & \multicolumn{2}{|c|}{ Cross Nikol } & \multicolumn{2}{c|}{ Paralel Nikol } \\
\cline { 2 - 5 } & $\begin{array}{c}\text { Akurasi } \\
(\%)\end{array}$ & $\begin{array}{c}\text { Waktu } \\
\text { (detik) }\end{array}$ & $\begin{array}{c}\text { Akurasi } \\
(\%)\end{array}$ & $\begin{array}{c}\text { Waktu } \\
\text { (detik) }\end{array}$ \\
\hline Gaussian & 78.064 & 94.882 & 83.950 & 94.807 \\
\hline Linear & 77.419 & 91.881 & 79.629 & 91.578 \\
\hline Polynomial & 72.903 & 91.993 & 80.246 & 91.726 \\
\hline
\end{tabular}

Pada Tabel 3 dapat dilihat untuk citra cross nikol didapat akurasi tertinggi $78.064 \%$ dengan waktu 91.88147 detik dengan kernel Gaussian, sedangkan untuk citra pararel nikol didapat akurasi tertinggi $83.950 \%$ dengan waktu 94.80739 detik dengan kernel Gaussian. Grafik pada akurasi skenario 2 terlihat pada Gambar 8, dimana akurasi terendah diperoleh pada Polymonial dengan cross. Selain itu, Gambar 9 menunjukan nilai durasi paling rendah pada Linear dengan parallel.

\subsection{Pengujian level dekomposisi DWT}

Pada pengujian skenario 3 ukuran citra yang digunakan adalah 1024 x 684 piksel, kernel SVM yang digunakan yaitu Gaussian, subband DWT LL, jumlah citra cross nikol yaitu 246 citra latih dan 155 citra uji sedangkan untuk jumlah citra paralel nikol yaitu 250 citra latih dan 162 citra uji. Citra tersebut dibagi ke dalam 6 kelas.

Pada Tabel 4 dapat dilihat bahwa untuk citra cross

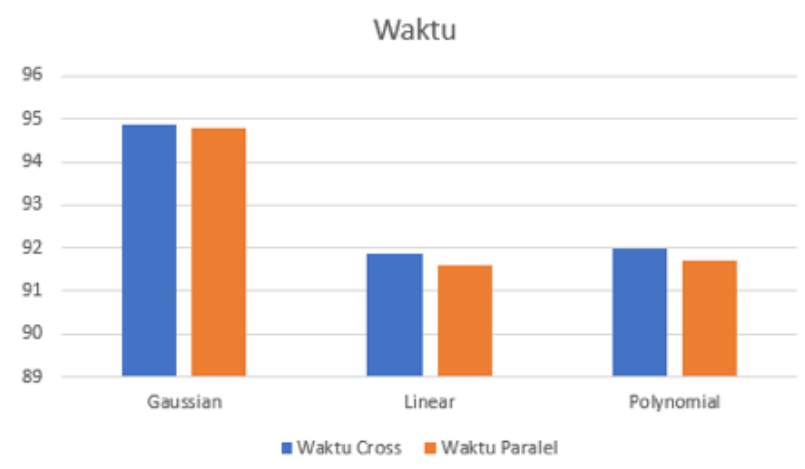

Gambar 9. Grafik waktu skenario 2.

Tabel 4. Hasil Pengujian Skenario 3

\begin{tabular}{|c|c|c|c|c|}
\hline \multirow{2}{*}{$\begin{array}{l}\text { Level } \\
\text { Dekom- } \\
\text { posisi }\end{array}$} & \multicolumn{2}{|c|}{ Cross Nikol } & \multicolumn{2}{|c|}{ Paralel Nikol } \\
\hline & $\begin{array}{c}\text { Akurasi } \\
(\%)\end{array}$ & $\begin{array}{l}\text { Waktu } \\
\text { (detik) }\end{array}$ & $\begin{array}{c}\text { Akurasi } \\
(\%)\end{array}$ & $\begin{array}{l}\text { Waktu } \\
\text { (detik) }\end{array}$ \\
\hline 1 & 78.064 & 100.098 & 83.950 & 95.399 \\
\hline 2 & 76.129 & 81.412 & 81.481 & 86.710 \\
\hline 3 & 75.483 & 83.166 & 83.333 & 88.319 \\
\hline 4 & 76.774 & 81.437 & 77.777 & 87.990 \\
\hline 5 & 75.483 & 82.034 & 72.222 & 86.539 \\
\hline 6 & 68.38 & 81.971 & 61.728 & 86.487 \\
\hline
\end{tabular}

nikol didapat akurasi tertinggi $78.064 \%$ dengan waktu 100.0981 detik dengan level dekomposisi 1, sedangkan untuk citra pararel nikol didapat akurasi tertinggi $83.950 \%$ dengan waktu 95.39991 detik pada level dekomposisi 1, seperti terlihat pada Gambar 10. Pada level dekomposisi 1 didapat akurasi tertinggi karena semakin besar level dekomposisi maka akan semakin kecil ukuran citra sehingga ketajaman dari citra juga semakin berkurang, seperti terlihat pada Gambar 10.

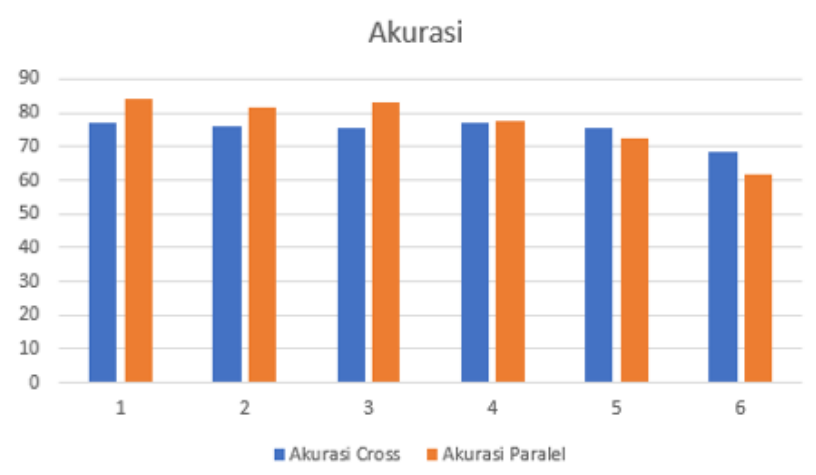

Gambar 10. Grafik akurasi skenario 3. 


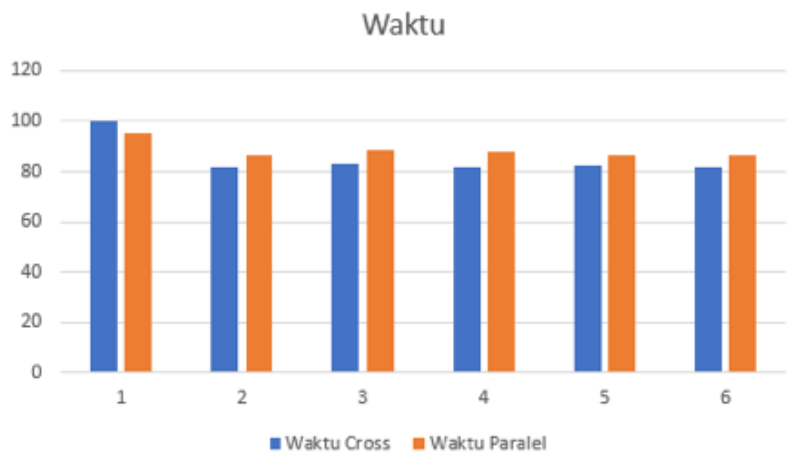

Gambar 11. Grafik waktu skenario 3.

\section{Kesimpulan}

Pada penelitian ini, dilakukan tiga skenario dengan nikol cross dan parallel, sehingga didapat hasil sebagai berikut :

1. Performasi tertinggi yang didapatkan setelah dilakukan pengujian pada sistem identifikasi tekstur dan warna mineral, untuk pengklasifikasian batuan beku dengan metode DWT dan SVM, yaitu akurasi $83.950 \%$ untuk citra paralel nikol dan 78.064\% untuk citra cross nikol, sedangkan untuk waktu komputasinya 94.80739 detik untuk citra paralel nikol dan 94.88281 detik untuk citra paralel nikol.

2. Parameter optimal yang digunakan pada metode DWT yaitu pada subband LL dan level dekomposisi 1.

3. Parameter optimal yang digunakan pada metode klasifikasi SVM yaitu dengan menggunakan kernel Gaussian.

\section{Daftar Pustaka}

[1] S. P. Nandi, "Handouts geologi lingkungan," Universitas Pendidikan Indonesia, 2010.

[2] I. Ramadhan, "Identifikasi daun shorea dengan backpropagation neural network menggunakan ekstraksi fitur discrete wavelet transform dan ekstraksi warna hsv [skripsi]," Bogor (ID): Institut Pertanian Bogor, 2012.

[3] I. Permatasari, Survey Sebaran Pasir Besi dengan Metode Geolistik Resistivitas (Tahana Jenis) Konfigurasi Dipole-dipole di Pantai Marina Kab. Bantaeng Sulawesi Selatan. PhD thesis, 2016.

[4] Taufiqurrohman, "Pengenalan plat sepeda motor dengan menggunakan metode jarak euclidean," Aug 2013.

[5] R. Munir, "Pengolahan citra digital dengan pendekatan algoritmik," Informatika, Bandung, 2004.

[6] S. G. Mallat, "A theory for multiresolution signal decomposition: the wavelet representation," IEEE Transactions on Pattern Analysis \& Machine Intelligence, no. 7, pp. 674-693, 1989.

[7] B. Santosa, "Tutorial support vector machine," Teknik Idustri, ITS.[Online]. Tersedia: http://www. google. co. id/url, 2010.

[8] A. S. Nugroho, A. B. Witarto, and D. Handoko, "Support vector machine teori dan aplikasinya dalam bioinformatika," Kuliah Umum Ilmu Komputer. com, 2003. 